\title{
The influence of leadership styles on employee engagement: The moderating effect of communication styles
}

\author{
Abdul Kadir Othman *, Muhammad Iskandar Hamzah, Mohd Khalid Abas, Nurzarinah Mohd Zakuan
}

Faculty of Business and Management, Universiti Teknologi MARA, 42300 Bandar Puncak Alam, Selangor, Malaysia

\section{A R T I C LE IN F O}

\section{Article history:}

Received 4 November 2016

Received in revised form

9 January 2017

Accepted 17 January 2017

\section{Keywords:}

Employee orientation

Change orientation

Production orientation, employee

engagement

Communication style

\begin{abstract}
A B S T R A C T
Employees are the important asset of an organization as they are the ones that determine the success or failure of the organization. Organizations that realize the importance of their employees have come out with various strategies and policies to ensure that their well-being is taken care of and they become engaged in their work. Apart from this consideration, leadership style is also expected to play a significant role in affecting employees' attitudes. This study is intended to investigate the influence of leadership style on employees' engagement by considering the moderating effect of leadership communication styles. A total of 112 data were collected from employees' via email. The results of a multiple regression analysis revealed that employee orientation leadership style is a significant predictor of employee engagement. Joining communication style significantly moderates the relationship between production orientation and employee engagement. Leaders who emphasize on production must use joining communication style so that the employee engagement level can be optimized.
\end{abstract}

(C) 2017 The Authors. Published by IASE. This is an open access article under the CC BY-NC-ND license (http://creativecommons.org/licenses/by-nc-nd/4.0/).

\section{Introduction}

With the stiff competition in the marketplace, organizations have put high emphasis on human capital or talent management. Human Resource Management has been given the top priority to ensure that the right talent is selected and recruited. Besides, various strategies have been devised and implemented to ensure that employees are fully developed and optimized to gain the highest level of productivity. To ensure that the talent is retained, fair remuneration and promotion is implemented. Although all these strategies seem to be adequate to motivate and retain the human capital with the organizations, in some instances they are not sufficient to make them engaged with the organizations. Other than the perennial matter of task-reward equity, several issues emerged that some experts fear that employee engagement may end up becoming just another 'HR fad' (Garrad and Chamorro-Premuzic, 2016; Guest, 2013).

Task fragmentation that arises from aggressive yet ill-planned outsourcing strategy, for example,

\footnotetext{
* Corresponding Author

Email Address: abdkadir@salam.uitm.edu.my (A. K. Othman) https://doi.org/10.21833/ijaas.2017.03.017

2313-626X/C 2017 The Authors. Published by IASE.

This is an open access article under the CC BY-NC-ND license

(http://creativecommons.org/licenses/by-nc-nd/4.0/)
}

may create functional silos that hinder people from being responsibly attached to their originally assigned tasks (Van Caeneghem and Bequevort, 2016). In another instance, employees that are overtly engaged with their work possibly would undermine the benefits of negative thinking by dismissing pessimistic instinct or temporary role of 'devil's advocate'. Such move may prove to be detrimental as it creates less fear and halting their spirit of breaking away from the status quo among the employees (Garrad and Chamorro-Premuzic, 2016). In tackling these issues, the creation of a sense of purpose and meaning in the employees' jobs is nothing short of essential. For that matter, leadership style is suggested to be the determinant of employee engagement. Undeniably, leaders are assigned as agents trusted by the organization to reinforce and instill the sense of purpose and meaning among the community of their followers.

\subsection{Employee engagement}

An engaged employee is considered to be emotionally attached to the organization, is passionate about his or her work, and cares about the success of the organization (Seijts and Crim, 2006). When employees are deeply engaged with an organization, there will be heightened sense of positive and intense feelings among them to exert 
their best effort for the success of the organization. It is more than just feeling satisfied with the workrelated factors in the organization. Macey and Schneider (2008) defined employee engagement as a desirable condition among employees that encompasses the following attributes (1) has an organizational purpose, (2) connotes involvement, commitment, passion, enthusiasm, focused effort and energy, and (3) involves both attitude and behavioural components. While work engagement involves employees' optimistic vibes towards their work, employee engagement deals with employees' positive feelings towards the organization. Apparently, employee engagement and work engagement are often used interchangeably in the literature partly due to the indistinct psychological needs and satisfaction that are associated with both constructs (Schaufeli, 2013). Nevertheless, engagement is theoretically distinguishable from other often overlapping constructs; namely, organizational commitment, citizenship behaviour and job involvement (Saks, 2006). Among the factors that are expected to lead to employee engagement is leadership style.

\subsection{Leadership style}

Apparently, a clear and precise consensus of leadership does not exist. There is no single accepted universal definition or theory of leadership (Gill, 2011). Nevertheless, transformational leadership is among the most discussed leadership style in the modern literature. Burns (1978) described transformational leaders as individuals who inspire and challenge subordinates to go beyond their personal interests in order to achieve goals or benefits to the wider group or organization. In contrast, transactional leadership explains the relationship between leader and follower as an exchange of well-defined transactions. Although transformational leadership is a fervent approach to visionary leaders and empowered followers among academicians and practitioners alike, the prominent theory has its own limitations. The crux of the problem lies within the insufficiency of the transformational leadership theory in addressing political, social and economic issues from the organizational context (Malloch, 2014).

Task and relationship centred leadership theories were among the earliest that contribute to the enrichment of the ideologies underlying today's various interpretation of leadership styles (Blake and Mouton, 1964; Fiedler, 1972). Considering that the model of task and relations orientation in leadership is too commonly used in research, Ekvall and Arvonen (1991) conceptualization of changecentred leadership is an added value in research. This is based on their argument that the twodimensional model of leadership (task versus relationship) may not be sufficient for firms to be competitive in a rapidly dynamic environment. Leadership styles are categorized into three dimensions comprising employee orientation, production orientation and change orientation (Ekvall and Arvonen, 1991) and it is simplified as the CPE model. Despite employee and production orientations reflect the essence of relationship and task centred leadership styles respectively, changecentered orientation is empirically proven as a valid construct that is independent from the two factors (Skogstad and Einarsen, 1999; Yukl et al., 2002). Limited studies have been carried out in areas outside the healthcare industry (which the CPE scales were widely used) and Scandinavian (as it is originated from Sweden) and western regions. Hence, its validity within this region is indeed a matter of interest among behavioural scholars. The CPE model is briefly described as Table 1.

Table 1: Ekvall and Arvonen (1991) CPE model description

\begin{tabular}{|c|c|c|}
\hline Dimensions & Definition & Relevant Underpinning Concepts/Theories \\
\hline Change-orientation & $\begin{array}{l}\text { Leader is interested in innovation, creativity } \\
\text { and new ways to accomplish tasks. By } \\
\text { learning and adapting in order to change the } \\
\text { status-quo, the leader is also a risk taker as } \\
\text { well. }\end{array}$ & $\begin{array}{c}\text { Developmental culture (Denison and Spreitzer, 1991), } \\
\text { openness to experience (Costa and McCrae, 1992), } \\
\text { double looped learning (Argyris, 1976) }\end{array}$ \\
\hline Production-orientation & $\begin{array}{l}\text { Leader concentrates effort on achieving } \\
\text { goals, thus engaging subordinates work } \\
\text { activities in task accomplishment roles. }\end{array}$ & $\begin{array}{l}\text { Rational culture (Denison and Spreitzer, 1991), } \\
\text { concern for production (Blake and Mouton, 1964), } \\
\text { need for achievement (McClelland, 1961) and Theory } \\
\text { X (McGregor, 1960) }\end{array}$ \\
\hline Employee-orientation & $\begin{array}{l}\text { Leader is sensitive to subordinates' needs, } \\
\text { thus the focus is on maintaining friendly and } \\
\text { supportive relationships through friendship, } \\
\text { mutual trust and respect. }\end{array}$ & $\begin{array}{l}\text { Group culture (Denison and Spreitzer, 1991), concern } \\
\text { for people (Blake and Mouton, 1964), need for } \\
\text { affiliation (McClelland, 1961), Theory Y (McGregor, } \\
\text { 1960) }\end{array}$ \\
\hline
\end{tabular}

\subsection{The relationship between leadership styles and employee engagement}

Previous studies were conducted to investigate the influence of various factors that might contribute to employee engagement. Among these factors, leadership styles have been found to be significant predictors of employee engagement. Among the leadership-related predictors are transformational leadership (Breevaart et al., 2014; Zhu et al., 2009), authentic leadership (Giallonardo et al., 2010), leadership position and 'team-supportive' leadership (Xu and Cooper, 2011) and charismatic leadership (Babcock-Roberson and Strickland, 2010). Furthermore, 'employee-engagement' competency of leaders in terms of respect for others and concern for their development and well-being are found to be a good predictor of employees' job performance, job 
satisfaction and organizational commitment (AlimoMetcalfe et al., 2008).

However, the findings of these studies are not consistent as some studies have discovered mixed results. There is a notable missing link between 'good management and mentoring' leadership style and employee engagement among entrepreneurial CEOs' subordinates (Papalexandris and Galanaki, 2009). 'Good management and mentoring' leadership style encapsulate management practices such as "administratively effective", "performance oriented", "role clarifying", "integrity", "selfconfident" and "intellectually stimulating", whereas elements of employee development practices are also included such as "follower confident", "power sharing", and "communicator" (Papalexandris and Galanaki, 2009). Furthermore, a study conducted using Britt et al. (2006) four-item scale of the single factor engagement construct indicates that transformational leadership brings no significant impact towards employee engagement while another study using Schaufeli et al. (2002) scale with the same criterion indicates an otherwise significant relationship (Wefald et al., 2011).

Markos and Sridevi (2010) underlined the dearth of research that link both leadership and employee engagement, especially in third world countries. Their argument made sense since much of the literature has been focusing on the western context, or within the nursing and teaching environment. In contrast to the western cultural values of individualism and low power distance, Malaysians are recognized as collectivists and have higher levels of power distance (Hofstede, 1991). Abdullah (2001) supported this view, highlighting the social norms of Malaysian employees such as group-oriented, respect towards elderly and loyalty. Hence, the way leadership is perceived and its impact on employee engagement in the local setting may provide a different insight from that of the western literature. Given the various incongruent interpretation of leadership styles, more research on how leadership have leverage in influencing levels of employee engagement is needed to understand the extent and ways in which such relationship occurs (Crawford et al., 2013). Based on the discussion, the following hypotheses are developed:

H1: Production orientation leadership style is significantly related to employee engagement.

$\mathrm{H}$ 2: Employee orientation leadership style is significantly related to employee engagement.

H3: Change orientation leadership style is significantly related to employee engagement.

\subsection{The moderating effects of communication styles on the relationship between leadership styles and employee engagement}

Given the several inconsistencies of previous findings, the present study was conducted to investigate the influence of leadership styles on employee engagement and to clarify to role of communication styles in influencing the relationship between leadership styles and employee engagement. The theoretical framework of this study integrates Ekvall and Arvonen (1991) CPE model and Richmond and McCroskey (1979) concept of management communication styles in predicting employee engagement. The management communication style is a continuation of Tannenbaum and Schmidt (2009) seminal work on the leadership continuum that gradually delineate the polarizing and dichotomous nature of autocratic versus democratic approach. Definitions of the four communication style dimensions are described in Table 2.

Table 2: Richmond and McCroskey (1979) management communication styles dimension

\begin{tabular}{|c|c|c|}
\hline Dimensions & Definition & Communication Direction \\
\hline Telling & $\begin{array}{c}\text { Manager provides top-down directive which is non-interactive and lack of } \\
\text { subordinates' concern. }\end{array}$ & Primarily downward and unidirectional. \\
\hline Selling & $\begin{array}{l}\text { Manager makes decisions by persuading subordinates to accept them. } \\
\text { Questions from subordinates are encouraged but counterarguments are } \\
\text { provided if the decisions are challenged. }\end{array}$ & $\begin{array}{l}\text { Primarily but not exclusively downward, } \\
\text { and sometimes bi-directional. }\end{array}$ \\
\hline Consulting & $\begin{array}{l}\text { Manager makes decisions only when problems and solutions have been } \\
\text { discussed with subordinates, to ensure that their well-being needs are met. }\end{array}$ & $\begin{array}{l}\text { Primarily upward, bi-directional and } \\
\text { interactive. }\end{array}$ \\
\hline Joining & $\begin{array}{l}\text { Manager delegates total authority to the subordinates, by setting the limit } \\
\text { within which the decisions must be made and allowing decision to be made } \\
\text { upon majority's opinion. }\end{array}$ & $\begin{array}{l}\text { Primarily horizontal, some } \\
\text { bi-directional and highly interactive. }\end{array}$ \\
\hline
\end{tabular}

Both leadership and communication effectively form a social fabric of an organization in which these two components are reciprocally embedded within the organization. Supportive leaders and clear communications positively enact social connectedness between managers and subordinates. For instance, Perceived Organizational Support and Leader-Member Exchange are found to positively moderate the relationship between employee engagement and organizational citizenship behaviour (Alfes et al., 2013). This is consistent with Soane (2013) contention that generating and sustaining social engagement is an important aspect of engaging leadership.

Besides the elaborated evidence of the causeeffect linkages between leadership styles and employee engagement, some studies have suggested that communication styles will exert a positive influence on leadership styles. Communication skills are partly essential in driving organizational change 
(Schaufeli, 2013), and thus are indispensable for change-oriented leaders to exert their influence in the right and meaningful way. Xu and Cooper (2011) suggested that transparent and honest communication enables production-oriented leaders increase their followers' engagement, especially among the leaders who are less able to develop their interpersonal skills. Leaders who are being transparent and consistent in communication are likely to be trusted by their followers. In turn, trust indirectly leads to employee work engagement through perceived authentic leadership (Hsieh and Wang, 2015). While leaders are encouraged to exercise open and clear communications, a 'Joining' communication style empowers the employees with ample opportunity for their voices to be heard. For an instance, employees' ability to speak up was found to be able to influence their engagement (Rees et al., 2013). Furthermore, the use of both directive and discursive communication makes the employees feel valued thus contributing to higher levels of employee engagement (Reissner and Pagan, 2013).

These suggestions and findings connote that communication is an established predictor of employee engagement. Therefore its hypothetical interaction effect on the linkage between leadership styles and employee engagement is clearly warranted. Effective communication strategies that effectively balance the act of authority and discretionary behaviours among leaders are expected to change the positive effects of their perceived leadership styles on their employees' engagement. Hence, the following hypotheses are highlighted:

H4: Telling communication style moderates the relationship between leadership styles and employee engagement.

H5: Selling communication style moderates the relationship between leadership styles and employee engagement.

H6: Consulting communication style moderates the relationship between leadership styles and employee engagement.

H7: Joining communication style moderates the relationship between leadership styles and employee engagement.

\section{Methodology}

The research used correlational design with the objective of testing the relationship between leadership styles and employee engagement, besides testing the moderating effects of communication styles on the main hypothesized relationship. The present study was carried out among the employees of Johnson Controls Automotive Sdn. Bhd. located in Shah Alam, Alor gajah, Pekan and Kulim, Malaysia. The total number of population is 693 and the sample size is 126 . The sample size is determined based on the Krejcie and Morgan (1970) table. The number of returned questionnaire is 112 making the response rate for the study to be $93.3 \%$. The instrument used in the study is a survey questionnaire, with items adapted from previous studies.

Items for leadership styles were adopted from Ekvall and Arvonen (1991) that comprise 36 items measuring change orientation (10 items), employee orientation (14 items) and production orientation leadership styles (12 items). The responses were captured using a 5-point Likert scales which ranging from 1 for strongly disagree to 5 for strongly agree. It was reported that the measure is highly reliable with Cronbach's alpha ranging from 0.78 to 0.88 . The sample item for change orientation is, "My leader encourages thinking along new lines", for employee orientation, the sample item is, "My leader relies on his/her subordinates", and for production orientation, the sample item is, "My leader creates order".

Employee engagement was measured using Schaufeli and Bakker (2003) 9-item of Utrecht Work Engagement Scale (UWES-9). This instrument measures three underlying dimensions of employee engagement; vigour, dedication, and absorption. Respondents in this study rated each item on a 5point Likert scale ranging from strongly disagree (1) to strongly agree (5). The reported Cronbach's alphas range from 0.70 to 0.95 for the three dimensions across 15 studies. The sample item for vigour is, "At my work, I feel bursting with energy", for dedication is, "I am enthusiastic about my job", and for absorption is, "I feel happy when I am working intensely".

Managerial communication styles were measured using Management Communication Scale, which was developed by Abdul et al. (2013) based on the conceptualization of the construct by Richmond and McCroskey (1979). The measure contains 27 items measuring telling (5 items), selling (8 items), consulting (6 items) and joining ( 8 items). The responses were gauged using a 5-point Likert scale that ranging from 1 for strongly disagree to 5 for strongly agree. It was reported that the measure is highly reliable with Cronbach's alpha of 0.92 . The sample items are "My manager receives decision from the top management and announces it to subordinates" (telling), "My manager persuades the subordinates of the desirability of decisions made by the top management or him/her" (selling), "My manager only makes final decisions after he/she has discussed it with the subordinates" (consulting), and "My manager always delegates decision-making to the subordinates" (joining).

The data were analyzed using descriptive, correlation and multiple regression analyses.

\section{Results and discussion}

Respondents were asked questions on their demographic characteristics including gender, age, marital status, ethnic group, education level, working experience and job position in order to understand the data distribution and representativeness of the samples (Table 3). 
Table 3: Respondents' profile

\begin{tabular}{|c|c|c|c|}
\hline Variable & Description & Frequency & $\%$ \\
\hline \multirow{2}{*}{ Gender } & Male & 46 & 41.1 \\
\hline & Female & 65 & 58.0 \\
\hline \multirow{4}{*}{ Age } & $\leq 25$ years & 14 & 12.5 \\
\hline & $25-35$ & 59 & 52.7 \\
\hline & $36-45$ & 30 & 26.8 \\
\hline & $46-55$ & 8 & 7.1 \\
\hline \multirow{3}{*}{ Marital Status } & Single & 31 & 27.7 \\
\hline & Married & 72 & 64.3 \\
\hline & Divorced & 8 & 7.1 \\
\hline \multirow{3}{*}{ Ethnic Group } & Malay & 88 & 78.6 \\
\hline & Chinese & 13 & 11.6 \\
\hline & Indian & 10 & 8.9 \\
\hline \multirow{5}{*}{ Education } & SPM/STPM/CERT & 19 & 17.0 \\
\hline & Diploma & 23 & 20.5 \\
\hline & Bachelor Degree & 51 & 45.5 \\
\hline & Master and PhD & 16 & 14.3 \\
\hline & Others & 1 & .9 \\
\hline \multirow{4}{*}{ Working Experience } & $\leq 4$ Years & 32 & 28.6 \\
\hline & 4-6 years & 33 & 29.5 \\
\hline & $7-9$ years & 9 & 8.0 \\
\hline & $\geq 10$ years & 36 & 32.1 \\
\hline \multirow{5}{*}{ Job Position } & Specialist & 51 & 45.5 \\
\hline & Clerk & 8 & 7.1 \\
\hline & Engineer & 17 & 15.2 \\
\hline & Supervisor & 16 & 14.3 \\
\hline & Others & 15 & 13.4 \\
\hline
\end{tabular}

Regarding gender, the number of female respondents is greater than male respondents (56 female respondents or $58 \%$ and 46 male respondents or $41.1 \%$ ). Pertaining to age group of respondents, 56 of them or $52.7 \%$ were in the age group of 25 to 35 years old, followed by those in the age group of 36 to 45 years old. A total of 14 respondents were aged less than 25 years old and the remaining eight respondents were aged between 46 to 55 years old. Examining their marital status, majority of respondents (72 or $64.3 \%$ ) were married while 31 respondents (27.7\%) were still single. Eight respondents were divorced. Out of 102 respondents, $88(78.6 \%)$ are Malays, $13(11.6 \%)$ are Chinese and $10(8.9 \%)$ are Indians. In terms of educational qualifications, 51 respondents (45.5\%) had bachelor degree, 23 respondents (20.5\%) had diploma, 19 respondents (17\%) had SPM/STPM/certificates, and 16 respondents had master degree or $\mathrm{PhD}$ as their highest academic qualifications. Concerning their working experience, 36 respondents (32.1\%) had been working for more than 10 years, followed by those with 4 to 6 years of experience, and those with less than 4 years of experience. Only nine respondents had 7 to 9 years of working experience on the job. Respondents involved in the study were mainly specialists with 51 representatives (45.5\%), followed those 17 (15.2\%) engineers, and 16 $(14.3 \%)$ supervisors. 15 respondents $(13.4 \%)$ did not respond to the item (Table 4).

A Principle Component factor analysis with varimax was conducted to determine the dimensionality of the items measuring the independent variables. Originally, there were 35 items measuring the three leadership styles; employee orientation (14 items), change orientation (12 items) and production orientation (nine items). The results of factor analysis indicate the existence of three factors as originally conceptualized; employee orientation (11 items), change orientation (8 items) and production orientation (8 items). A total of 8 items were removed due to high cross loadings or loadings different from the original conceptualization. The 27 items explained 66.41 of the total variance in the model which is above the minimum percentage of $60 \%$. The KMO value is $0.921\left(\chi^{2}=2272.989, \mathrm{p}<0.01\right)$, indicates that the correlation index is suitable for factor analysis to be conducted. The MSA values are in the range of 0.838 to 0.971 , indicating adequate correlation index for each item which is suitable to be factor analyzed.

The first component reflects employee orientation, which explains $27.443 \%$ of the variance in the leadership style model. Three items were removed due to high cross loadings or loadings different from the proposed model. The loadings range from 0.709 to 0.847 . The original name remains. The second factor corresponds to change orientation, which explains $20.552 \%$ of the variance in the model. Four items were deleted due to high cross leadings or loadings different from the original model. The loadings of the remaining items range from 0.586 to 0.813 . The original name was used. The third component concerns production orientation of leaders, which explains $18.415 \%$ of the variance in the model. One item was removed because of high cross loadings or loadings different from the original model. The loadings of the eight items range from 0.582 to 0.726 . The original name of production orientation was retained (Table 5).

A principle factor analysis was also performed to determine the dimensionality of the dependent variable; work engagement. Initially, there are nine items measuring the intended variable. However, the outcome of factor analysis indicates the existence of one factor with eight items. One item was removed to low leadings. The uni-dimensional variable explained $69.268 \%$ of the variance in the model, which exceeds the recommended threshold value of $60 \%$. The KMO value of 0.887 indicates the factor matrix allows factor analysis to be conducted. The MSA values ranging from 0.884 to 0.914 indicate that there are sufficient correlation coefficients for each item. The loadings ranging from 0.794 to 0.880 are high enough to indicate the dimensionality of the factor. The original name of employee engagement was retained (Table 6).

A principle component of factor analysis with varimax rotation was also performed for the moderator variables; Management Communication Style. At the beginning, there were five items for telling communication style, three items for selling communication style, five items for consulting communication style, and five items for joining communication style. After factor analysis was conducted, 11 items were retained and seven items removed due to high cross loadings and items loaded 
differently from the original conceptualization. The four factors explained $80.144 \%$ of the variance in the model $(25.6 \%$ for joining communication style, $20.7 \%$ for telling communication style, $16.95 \%$ for consulting communication style, and $16.8 \%$ for selling communication style). The KMO value of 0.832 indicates the suitability of factor analysis to be performed. The MSA values ranging from 0.713 to 0.920 denote the adequacy of the correlation matrix for the items.

Table 4: Results of factor analysis of the independent variables

\begin{tabular}{|c|c|c|c|}
\hline \multirow[b]{3}{*}{ Employee Orientation } & \multicolumn{3}{|c|}{ Component } \\
\hline & 1 & 2 & 3 \\
\hline & & & \\
\hline My leader is considerate & 0.847 & & \\
\hline My leader is flexible and ready to rethink his / her point of view & 0.789 & & \\
\hline My leader creates trust in other people & 0.785 & & \\
\hline My leader stands up for his / her subordinates & 0.778 & & \\
\hline My leader has an open and honest style & 0.773 & & \\
\hline My leader is just in treating subordinates & 0.773 & & \\
\hline My leader creates an atmosphere free of conflict & 0.772 & & \\
\hline My leader allows his / her subordinates to decide & 0.733 & & \\
\hline My leader listens to ideas and suggestions & 0.727 & & \\
\hline My leader criticizes in a constructive way & 0.719 & & \\
\hline My leader shows regard for the subordinates as individuals & 0.709 & & \\
\hline \multicolumn{4}{|l|}{ Change Orientation } \\
\hline My leader experiments with new ways of doing things & & 0.813 & \\
\hline My leader sees possibilities rather than conflicts & & 0.748 & \\
\hline My leader initiates new projects & & 0.744 & \\
\hline My leader encourages thinking along new lines & & 0.691 & \\
\hline My leader likes to discuss new ideas & & 0.669 & \\
\hline My leader offers ideas about new and different ways of doing things & & 0.666 & \\
\hline My leader is willing to take risks in decisions & & 0.661 & \\
\hline My leader makes quick decisions when necessary & & 0.586 & \\
\hline \multicolumn{4}{|l|}{ Production Orientation } \\
\hline My leader is controlling in his / her supervision of work & & & 0.726 \\
\hline My leader makes a point of following rules and principles & & & 0.706 \\
\hline My leader creates order & & & 0.694 \\
\hline My leader gives information about the results of the unit & & & 0.666 \\
\hline My leader is very clear about who is responsible for what & & & 0.658 \\
\hline My leader pushes for growth & & & 0.657 \\
\hline My leader is very exacting about plans being followed & & & 0.612 \\
\hline My leader defines and explains the work requirement clearly & & & 0.582 \\
\hline$\%$ variance explained $(66.410)$ & 27.443 & 20.552 & 18.415 \\
\hline Kaiser-Meyer-Olkin Measure of Sampling Adequacy & & & 0.921 \\
\hline Bartlett's Test of Sphericity & \multirow{4}{*}{\multicolumn{2}{|c|}{$\begin{array}{c}\text { Approx. Chi-Square } \\
\text { Df } \\
\text { Sig. }\end{array}$}} & 2272.989 \\
\hline & & & 351 \\
\hline & & & 0.000 \\
\hline MSA & & & 0.838-0.971 \\
\hline
\end{tabular}

Table 5: Results of factor analysis of the dependent variable

\begin{tabular}{lcc}
\hline & \multicolumn{2}{c}{ Component } \\
\cline { 2 - 3 } At my job, I feel strong and vigorous & 0.880 \\
\cline { 2 - 3 } My job inspires me & 0.861 \\
When I get up in the morning, I feel like going to work & 0.846 \\
I am proud of the work that I do & 0.832 \\
I am immersed in my work & 0.827 \\
I am enthusiastic about my job & 0.809 \\
I feel happy when I am working intensely & 0.806 \\
At my work, I feel bursting with energy & 0.794 \\
\% variance explained & 69.268 \\
Kaiser-Meyer-Olkin Measure of Sampling Adequacy & \multicolumn{2}{c}{0.887} \\
\multicolumn{1}{c}{ Bartlett's Test of Sphericity } & Approx. Chi-Square & 692.860 \\
& Df & 28 \\
& Sig. & 0.000 \\
& \multicolumn{2}{c}{$0.844-0.914$} \\
\hline
\end{tabular}

The first component contains four items measuring joining communication style with loadings which range from 0.716 to 0.827 . One item was removed due to high cross loadings. The original name was retained. For the second component, three items loaded highly on this factor known as telling communication style. Two items were removed as they cross loaded under different components. The loadings range from 0.582 to 0.896 and its original name was retained. The third contained only two factors (out of five original items) with loadings which range from 0.767 to 0.911 . These items are meant to measure consulting communication style and the name was used. The last component reflects 
selling communication style containing only two items (there are originally three items) measuring with loadings which range from 0.729 to 0.816 . The original name was kept (Table 7).

Table 6: Results of factor analysis of the moderating variables

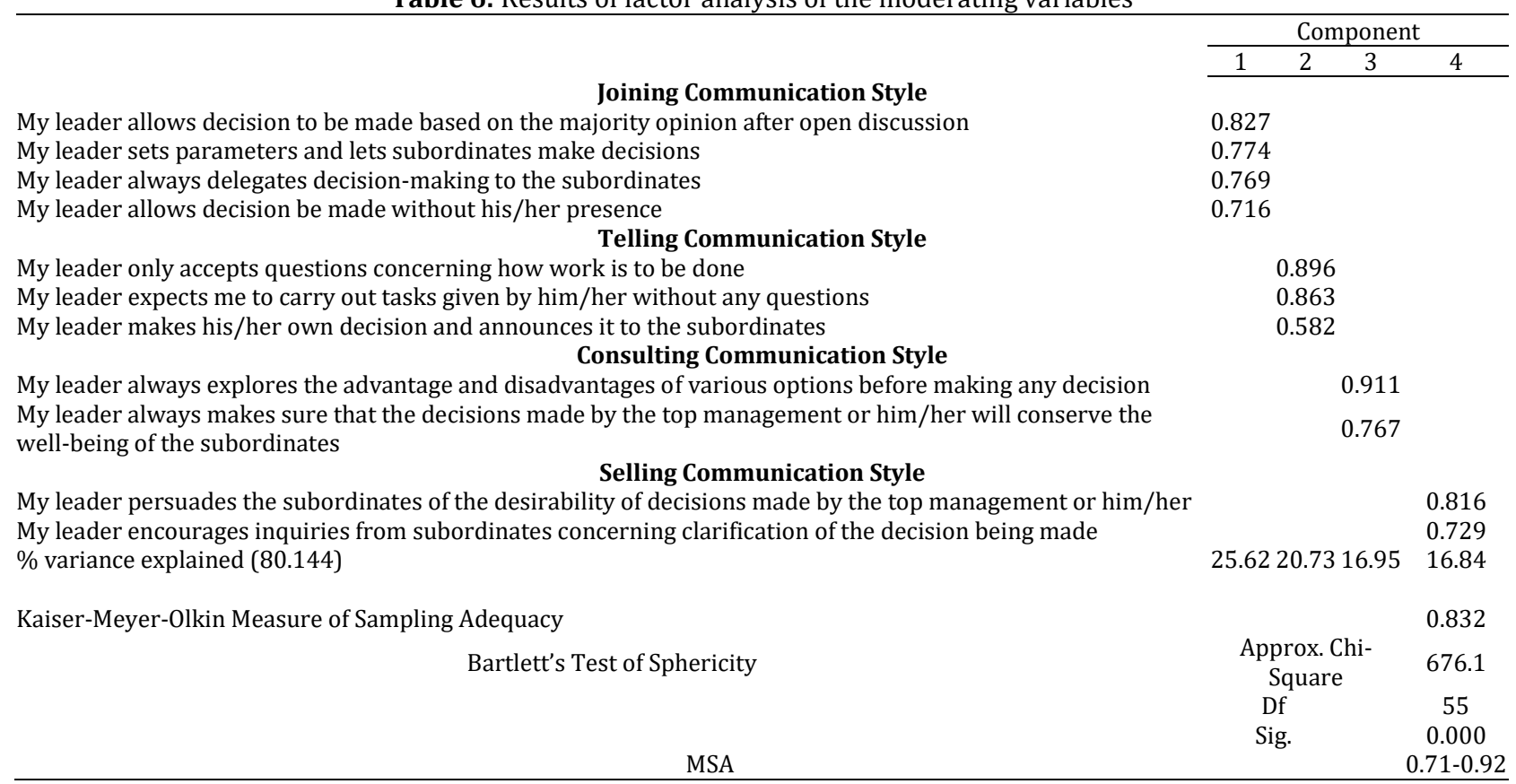

Table 7: Results of correlation and reliability analysis

\begin{tabular}{|c|c|c|c|c|c|c|c|c|c|c|c|}
\hline No & Variables & Mean & SD & 1 & 2 & 3 & 4 & 5 & 6 & 7 & 8 \\
\hline 1 & Employee orientation & 3.28 & 0.60 & $(0.951)$ & & & & & & & \\
\hline 2 & Change orientation & 3.25 & 0.57 & $0.610^{* *}$ & $(0.923)$ & & & & & & \\
\hline 3 & Production orientation & 3.34 & 0.54 & $0.627^{* *}$ & $0.798^{* *}$ & $(0.912)$ & & & & & \\
\hline 4 & Employee engagement & 3.95 & 0.65 & $0.483^{* *}$ & $0.383^{* *}$ & $0.405^{* *}$ & $(0.935)$ & & & & \\
\hline 5 & Joining & 3.56 & 0.82 & $0.633^{* *}$ & $0.620^{* *}$ & $0.587^{* *}$ & $0.528^{* *}$ & $(0.878)$ & & & \\
\hline 6 & Telling & 3.44 & 0.85 & 0.083 & $0.265^{* *}$ & $0.260^{* *}$ & $0.252^{* *}$ & $0.389^{* *}$ & $(0.805)$ & & \\
\hline 7 & Consulting & 3.81 & 0.87 & $0.414^{* *}$ & $0.407^{* *}$ & $0.423^{* *}$ & 0.158 & $0.540^{* *}$ & -0.100 & $(0.815)$ & \\
\hline 8 & Selling & 3.86 & 0.72 & $0.485^{* *}$ & $0.580^{* *}$ & $0.633^{* *}$ & $0.460^{* *}$ & $0.629^{* *}$ & $0.407^{* *}$ & $0.410^{* *}$ & $(0.788)$ \\
\hline
\end{tabular}

Examining the relationship between the variables, all the independent variables (employee orientation, change orientation and production orientation) are highly correlated with each other, signifying convergent validity. The $r$ values range from 0.610 to 0.798 . On the other hand, the independent variables are lowly and moderately correlated with the dependent variable (employee engagement, denoting concurrent validity). The $r$ values range from 0.383 to 0.483 . Besides, the independent variables and the moderator variables (joining, telling, consulting and selling communication styles) are highly and moderately moderated with each other. The $r$ values are in the range of 0.083 and 0.633 . The relationships between the moderator variables and the dependent variable range from very low to moderate. The values are between 0.158 and 0.528 . These findings indicate potential moderating effects of employee engagement on the relationship between leadership styles and employee engagement (Table 8 and Fig. 1).

The interaction between joining communication style and production orientation and how this interaction affects employee engagement can be clearly depicted using the interaction graph above. The graph was constructed using the categorical data (low and high) of production orientation and joining communication style which had been transformed earlier using the median values. The graph explains that when leaders use low levels of joining communication style, the increase in the degree of production orientation will result in lower levels of employee engagement. However, when leaders use high levels of joining communication style although there is an increase in production orientation, employee engagement will intensify.

Among the three leadership styles offered in the CPE model, production orientation is where leaders should put their emphasis on. In high production orientation, they set high targets for employees to achieve. When leaders set the target alone without the involvement from their subordinates, they will face difficulties in securing the employees' engagement. However, when the target is set with the involvement of the employees via joining communication style, employees will feel that they are part of the deciding team. As a result, their level of engagement will improve significantly.

This finding indicates that leaders can successfully use production orientation in their leadership style provided that they also implement joining communication style; getting the employees involved in the decision making process. This 
discovery is in consistent with previous reported findings (Rees et al., 2013; Reissner and Pagan, 2013). Employees whose voices are equally heard allow them to feel valued, and thus contributing to their increased engagement towards their job
(Reissner and Pagan, 2013). Furthermore, employees who perceive themselves as speaking up issues, opinions and ideas are more likely to be engaged with their work (Rees et al., 2013).

Table 8: Results of multiple regression analysis

\begin{tabular}{|c|c|c|c|c|c|c|c|c|c|c|c|c|}
\hline & \multicolumn{3}{|c|}{ Tell } & \multicolumn{3}{|c|}{ Sell } & \multicolumn{3}{|c|}{ Join } & \multicolumn{3}{|c|}{ Consult } \\
\hline Independent variables & M1 & M2 & M3 & M1 & M2 & M3 & M1 & M2 & M3 & M1 & M2 & M3 \\
\hline Employee orientation & $0.449 * *$ & $0.508^{* *}$ & 0.600 & $0.449^{* *}$ & $0.417^{* *}$ & 0.234 & $0.449^{* *}$ & $0.315^{* *}$ & $0.523^{*}$ & $0.449 * *$ & 0.447 & $0.574^{*}$ \\
\hline Change orientation & -0.025 & -0.098 & 0.631 & -0.025 & -0.077 & -0.045 & -0.025 & -0.135 & -0.356 & -0.025 & -0.026 & -0.295 \\
\hline Production orientation & 0.095 & 0.060 & -0.349 & 0.095 & 0.003 & -0.276 & 0.095 & 0.070 & $-0.716^{*}$ & 0.095 & 0.093 & -0.337 \\
\hline Moderator & & $0.228^{*}$ & 0.757 & & $0.282^{* *}$ & -0.190 & & $0.367^{* *}$ & $-0.876^{*}$ & & 0.010 & $-0.912^{*}$ \\
\hline \multicolumn{13}{|c|}{ Interaction terms } \\
\hline $\begin{array}{c}\text { Employee } \\
\text { orientation*Moderator }\end{array}$ & & & -0.160 & & & 0.304 & & & -0.603 & & & -0.378 \\
\hline $\begin{array}{l}\text { Change orientation } \\
\text { *Moderator }\end{array}$ & & & -1.403 & & & -0.038 & & & 0.592 & & & 0.711 \\
\hline $\begin{array}{c}\text { Production } \\
\text { orientation*Moderator }\end{array}$ & & & 0.804 & & & 0.523 & & & $1.822^{*}$ & & & 0.947 \\
\hline $\mathrm{R}$ & 0.495 & 0.539 & 0.553 & 0.495 & 0.547 & 0.558 & 0.495 & 0.569 & 0.645 & 0.495 & 0.495 & 0.540 \\
\hline $\mathrm{R}^{2}$ & 0.245 & 0.290 & 0.306 & 0.245 & 0.299 & 0.263 & 0.245 & 0.323 & 0.416 & 0.245 & 0.245 & 0.291 \\
\hline Adjusted $\mathrm{R}^{2}$ & 0.223 & 0.263 & 0.257 & 0.223 & 0.272 & 0.263 & 0.223 & 0.297 & 0.375 & 0.223 & 0.216 & 0.241 \\
\hline F Change & 11.245 & 6.613 & 0.737 & 11.245 & 7.974 & 0.568 & 11.245 & 11.959 & 5.249 & 11.245 & 0.010 & 2.167 \\
\hline Sig. F Change & 0.000 & 0.012 & 0.532 & 0.000 & 0.006 & 0.618 & 0.000 & 0.001 & 0.002 & 0.000 & 0.920 & 0.097 \\
\hline Durbin Watson & & & 1.638 & & & 1.621 & & & 1.768 & & & 1.503 \\
\hline
\end{tabular}

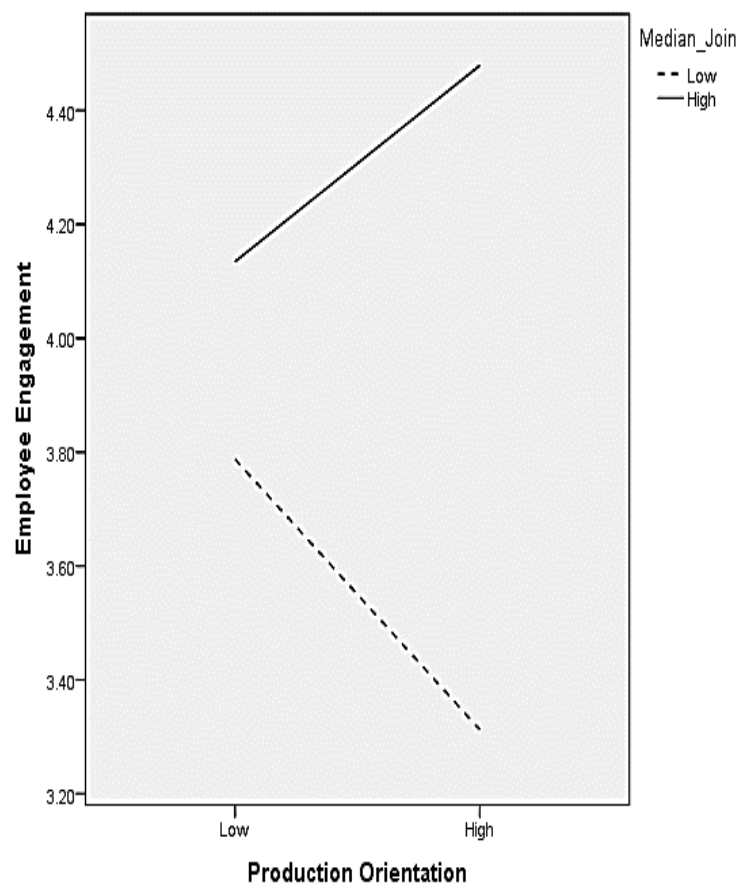

Fig. 1: The interaction between joining communication style and production orientation to affect engagement

The paradoxical outcome of this research comes from the insignificance of change-oriented leadership in becoming a predictor of employee engagement. In particular, the hypothesized relationship between change-oriented leadership style and employee engagement as being significantly moderated by communication styles, received little empirical support from the analysis. One of the explanations can perhaps be attributed to the ownership status of the leader in the firm where the employees are recruited. Specifically, the effects of visionary articulation by leaders (CEO) on employee engagement is significantly moderated by entrepreneurial ownership of the firm by CEOs themselves, while the result becomes insignificant if the CEO do not hold any ownership and is a salaried professional (Papalexandris and Galanaki, 2009). On another note, the influence of change-centred leadership on employees' wellbeing can be diverse according to the cultural values instilled within the firms. The effect of change-oriented leadership on employees' job satisfaction is insignificant particularly in a rational culture setting as compared to other three cultural values (Skogstad and Einarsen, 1999).

While the result do not convincingly support change-oriented culture as a preferred culture in shaping positive work engagement, it is imperative for researchers to exercise caution before making conclusions, considering the deficiency in generalizing what this work has to offer. Notwithstanding, further research is needed to understand the impact of change-oriented leadership on employee engagement. Results of the same construct can be diverse across different scales used. As noted by Wefald et al. (2011), the relationship between transformational leadership and employee engagement becomes significant when Schaufeli et al. (2002) measure was used as compared to Britt et al. (2006) scale which yielded insignificant results. Thus, the pursuit of discovering the predictive ability of change-oriented leadership on employee engagement should not just be put into a halt.

\section{Conclusion}

One of the issues besieging organizations is how to ensure that their human capital is fully engaged, as engaged employees are more than happy to help their organizations prosper. The present study confirmed that leadership style, in particular, employee oriented leadership style contributes in ensuring the high levels of engagement among the employees in the organization. This study also discovered that join communication style moderates 
the relationship between production oriented leadership style and employee engagement. Production oriented leadership style can be used to enhance the levels of employee engagement when leaders also involve employees in the decision making process. The findings of the study bring some significant implications to the organizations.

\subsection{Managerial implications}

To ensure that the employees are fully engaged, managers or leaders must practice employee oriented leadership style. The employees are fairly treated, they are treated as human beings, decisions are made considering the needs and the capability of the employees, the leaders criticize in an acceptable manner, they also create an environment free of conflict and other actions that focus on the wellbeing of the employees. The finding is consistent with the assumption that those who have favourable emotions will react positively by showing desirable behaviours. Therefore, leaders must ensure that their subordinates' are happy working with the organization.

Some leaders are production oriented whereby achieving the target is highly significant beyond other things due to high market demands. They can implement this leadership style provided that they practice joining communication style whereby employees are involved in setting the target and deciding how to achieve the target. By doing this, the needs and the ability of the employees are positioned in the right perspective. Some practical recommendations are ensuring the involvement of employees or their representatives in the top management meeting, creating a 'suggestion box' for the employees to forward their ideas or opinions, and having regular round table dialogues with all employees such as during weekly gatherings.

\subsection{Suggestion for future research}

The present study was conducted in a specific research setting involving a manufacturing group of companies. The results of the study may not be applicable to others. Future studies are recommended to expand their scope to include more representatives. The present study focused on only three types of leadership styles. There are other leadership styles practiced by leaders, which were not included in the study. Therefore, the findings are not comprehensive to determine the leadership styles that contribute to employee engagement. Future studies should be conducted comprehensively by considering other leadership styles that are popular among leaders. The present study only considered communication styles as the possible moderators in its framework. In future, other moderators should be taken into consideration such as organizational structure (team versus individual), organizational culture (integration versus adaptation) and organizational nature (product versus service).

\section{References}

Abdul AR, Mokhtar M, and Norlida K (2013). Validity and reliability of the management communication style scale. International Journal of Social Science and Humanity, 3(4): 390-395.

Abdullah A (2001). Influence of ethnic values at the Malaysian workplace. In: Abdullah A and Low A (Eds.), Understanding the Malaysian Workforce: Guidelines for Managers: 1-24. Malaysian Institute of Management, Kuala Lumpur, Malaysia.

Alfes K, Shantz AD, Truss C, and Soane EC (2013). The link between perceived human resource management practices, engagement and employee behaviour: A moderated mediation model. International Journal of Human Resource Management, 24(2): 330-351.

Alimo-Metcalfe B, Alban-Metcalfe J, Bradley M, Mariathasan J, and Samele C (2008). The impact of engaging leadership on performance, attitudes to work and wellbeing at work: a longitudinal study. Journal of Health Organization and Management, 22(6): 586-598.

Argyris C (1976). Single-loop and double-loop models in research on decision making. Administrative Science Quarterly, 21(3): 363-375.

Babcock-Roberson ME and Strickland OJ (2010). The relationship between charismatic leadership, work engagement, and organizational citizenship behaviors. Journal of Psychology, 144(3): 313-326

Blake R and Mouton J (1964). The management grid: The key to leadership excellence. Gulf Publishing Co., Houston, USA.

Breevaart K, Bakker A, Hetland J, Demerouti E, Olsen OK, and Espevik R (2014). Daily transactional and transformational leadership and daily employee engagement. Journal of Occupational and Organizational Psychology, 87(1): 138-157.

Britt TW, Thomas JL, and Dawson CR (2006). Self-engagement magnifies the relationship between qualitative overload and performance in a training setting. Journal of Applied Social Psychology, 36(9): 2100-2114.

Burns JM (1978). Leadership. Harper and Row. New York, USA

Costa PT and McCrae RR (1992). Four ways five factors are basic. Personality and Individual Differences, 13(6): 653-665.

Crawford ER, Rich BL, Buckman B, and Bergeron J (2013). The antecedents and drivers of employee engagement. In: Truss $C$, Alfes K, Delbridge R, Shantz A, and Soane EC (Eds.), Employee Engagement in Theory and Practice: 57-81. Routledge, London, UK

Denison DR and Spreitzer GM (1991). Organizational culture and organizational development: A competing values approach. Research in Organizational Change and Development, 5(1): 121.

Ekvall G and Arvonen J (1991). Change-centered leadership: An extension of the two-dimensional model. Scandinavian Journal of Management, 7(1): 17-26

Fiedler FE (1972). The effects of leadership training and experience: A contingency model interpretation. Administrative Science Quarterly, 17(4): 453-470.

Garrad L and Chamorro-Premuzic T (2016). The dark side of high employee engagement. Available online at: https://hbr.org/2016/08/the-dark-side-of-high-employeeengagement

Giallonardo LM, Wong CA, and Iwasiw CL (2010). Authentic leadership of preceptors: predictor of new graduate nurses' work engagement and job satisfaction. Journal of Nursing Management, 18(8): 993-1003.

Gill R (2011). Theory and practice of leadership. SAGE Publications, California, USA. 
Guest DE (2013). Employee engagement: Fashionable fad or longterm fixture?. In: Truss C, Alfes K, Delbridge R, Shantz A, and Soane EC (Eds.), Employee Engagement in Theory and Practice: 221-235. Routledge, London, UK.

Hofstede G (1991). Management in a multicultural society. Malaysian Management Review, 26(1): 3-12.

Hsieh CC and Wang DS (2015). Does supervisor-perceived authentic leadership influence employee work engagement through employee-perceived authentic leadership and employee trust?. International Journal of Human Resource Management, 26(18): 2329-2348.

Krejcie RV and Morgan DW (1970). Determining sample size for research activities. Educational and Psychological Measurement, 30(3): 607-610.

Macey WH and Schneider B (2008). The meaning of the employee engagement. Industrial and Organizational Psychology, 1(1): 3-30.

Malloch K (2014). Beyond transformational leadership to greater engagement: Inspiring innovation in complex organizations. Nurse Leader, 12(2): 60-63.

Markos S and Sridevi MS (2010). Employee engagement: The key to improving performance. International Journal of Business and Management, 5(12): 89-96.

McClelland DC (1961). The achievement society. Von Nostrand, New Jersey, USA.

McGregor D (1960). Theory X and Y. Organization Theory: Selected Readings. Penguin Publishing, London, UK.

Papalexandris N and Galanaki E (2009). Leadership's impact on employee engagement: Differences among entrepreneurs and professional CEOs. Leadership and Organization Development Journal, 30(4): 365-385.

Rees C, Alfes K, and Gatenby M (2013). Employee voice and engagement: connections and consequences. International Journal of Human Resource Management, 24(14): 2780-2798.

Reissner S and Pagan V (2013). Generating employee engagement in a public-private partnership: management communication activities and employee experiences. International Journal of Human Resource Management, 24(14): 2741-2759.

Richmond VP and McCroskey JC (1979). Management communication style, tolerance for disagreement, and innovativeness as predictors of employee satisfaction: A comparison of single factor, two-factor, and multiple-factor approaches. In: Nimmo D (Eds.), Communication yearbook 3: 359-373. Transaction Publishers, New Brunswick, Canada.
Saks AM (2006). Antecedents and consequences of employee engagement. Journal of Managerial Psychology, 21(7): 600619.

Schaufeli WB (2013). What is engagement?. In: Truss C, Alfes K, Delbridge R, Shantz A, and Soane EC (Eds.), Employee engagement in theory and practice: 15-35. Routledge, London, UK.

Schaufeli WB and Bakker AB (2003). Utrecht work engagement scale: Preliminary manual. Utrecht University, Netherlands.

Schaufeli WB, Salanova M, González-Romá V, and Bakker AB (2002). The measurement of engagement and burnout: A two sample confirmatory factor analytic approach. Journal of Happiness Studies, 3(1): 71-92.

Seijts GH and Crim D (2006). What engages employees the most or, the ten C's of employee engagement. Ivey Business Journal, 70(4): 1-5.

Skogstad A and Einarsen S (1999). The importance of a changecentred leadership style in four organizational cultures. Scandinavian Journal of Management, 15(3): 289-306.

Soane EC (2013). Leadership and employee engagement. In: Truss C, Alfes K, Delbridge R, Shantz A and Soane EC (Eds.), Employee Engagement in Theory and Practice: 149-162. Routledge, London, UK.

Tannenbaum R and Schmidt WH (2009). How to choose a leadership pattern. Harvard Business Review, Massachusetts, USA.

Van Caeneghem A and Bequevort J (2016). How fragmentation is killing employee engagement. Available online at: http://ww2.cfo.com/staffing/2016/08/fragmentation-killingemployee-engagement.

Wefald AJ, Reichard RJ, and Serrano SA (2011). Fitting engagement into a nomological network the relationship of engagement to leadership and personality. Journal of Leadership and Organizational Studies, 18(4): 522-537.

Xu J and Cooper TH (2011). How can leaders achieve high employee engagement? Leadership and Organization Development Journal, 32(4): 399-416.

Yukl G Gordon A and Taber T (2002). A hierarchical taxonomy of leadership behavior: Integrating a half century of behavior research. Journal of Leadership and Organizational Studies, 9(1): 15-32.

Zhu W, Avolio BJ, and Walumbwa FO (2009). Moderating role of follower characteristics with transformational leadership and follower work engagement. Group and Organization Management, 34(5): 590-619. 